\title{
HPV VACCINE FOR BOYS
}

The BDJ Upfront section includes editorials, letters, news, book reviews and interviews. Please direct your correspondence to the News Editor, Kate Quinlan at the BDJ, The Macmillan Building, 4 Crinan Street, London, N1 9XW or by email to k.quinlan@nature.com

Press releases or articles may be edited, and should include a colour photograph if possible.

Stephen Hancocks OBE

Editor-in-Chief

$\mathrm{T}$ here are certain things in life that seem obvious, so obvious in fact that once heard one wonders what the barriers are to implementing them. The case for vaccinating boys in the UK against the human papilloma virus (HPV) has been very well made recently in this journal ${ }^{1}$ and elsewhere, including by Professor Margaret Stanley at the launch of Mouth Cancer Awareness Month last October.

It is a matter of importance for us in dentistry because the virus is implicated in oral cancer and is of particular significance because the number of people being diagnosed with this distressing condition is on the increase. HPV is believed to be the causal agent in 5\% of all human cancers and is now the major cause of oropharyngeal cancer in developed countries, detected in up to $90 \%$ of cases. This seems to be particularly so in younger people, a trend that was first noted as a possibility some years ago when there was an otherwise unexplained rise in oral cancers in this cohort and suggested that it may be due to the virus being transmitted through oral sex. At that time, as now, the majority of sufferers are above middle-age and the main risk factors include heavy tobacco and alcohol consumption. But having detected the trend in younger age groups and identified the likely causative agent, it seems foolish to either ignore the mounting evidence or wait any longer to take preventive action.

The government has already effectively accepted this evidence by implementing a vaccination programme for its current target group of 12/13 year old girls, yet this must now be viewed against a background of the increasing number of cases

\section{'It seems \\ foolish to ignore the mounting evidence or wait any longer...'}

(c)

of HPV-caused cancers in men. By vaccinating both genders there will be a increasing herd immunity which helps to ensure those otherwise marginalised by geographic or socioeconomic determinants have a better chance of protection.

Vaccinating males would also aid in protecting females in these groups from cervical cancer and other HPVrelated diseases. Males themselves would similarly be protected from HPV infection by non-vaccinated females, from the UK or elsewhere, and by other males. Significantly, the current girls-only vaccination programme leaves men who have sex with men at particular risk of infection because they do not benefit from any herd protection. So, whilst the thrust of the argument is to do with prevention there is inevitably a question of equality involved too.

The HPV family of viruses is large but it is HPV 16 that is the villain being implicated in 13 different cancer types including cervical, vaginal, penile, oral and laryngeal as well as genital warts, which can also manifest orally. In the letter from Thavaral and Odell in this issue ${ }^{2}$ the authors point out that HPV-related oral cancers are still very much in the minority and that HPV infection is primarily associated with carcinomas of the tonsil and oropharynx; yet vaccination would prevent these too. Although implication of HPV infection cannot be confirmed until biopsy of a suspected cancer, from the patient's viewpoint it can only by then be of academic interest as to how that infection might have been derived or transmitted. Surely it is so much more humane and sensible to prevent it from happening at all?

It is therefore very pleasing that the BDA has also now thrown its weight behind the campaign for vaccination of boys as the letter from Stokes outlines in this issue. ${ }^{3}$ This lends further credence to the case that we have made here in recent years that as dentists and dental teams we have to become far more engaged in both wider health and medical issues, as well as politically more astute and socially conscious. To this end readers are encouraged to write to and lobby their respective members of parliament and/or the public health minister Jane Ellison MP at the Department of Health as well as visiting HPV Action's website at www.hpvaction.org.

Vaccination also has one other important advantage in that it overrides claims that young people in particular should be taught to restrain themselves sexually, reducing promiscuity and the chances of contracting sexually transmitting disease (STD). Voluntary restraint is demonstrably ineffectual as levels of teenage pregnancy (the UK has amongst the highest rates in Europe) and STDs rise. Oral sex is a fact of twenty-first century life (and it has hardly been invented recently anyway) and it is a subject that, until vaccination is more widespread, may also be appropriate to discuss with some of our patients. If talking about tobacco and alcohol habits have seemed like difficult subjects to raise then talking about oral sex may present a further challenge but it is one we need to consider. It is, I'm afraid, obvious.

1. Baker P. Vaccinating boys against HPV. BrDent J 2013; 215: 543-544.

2. Thavaraj $\mathrm{S}$, Odell E. Psychosocial implications. Br Dent J 2014; 216: 3.

3. Stokes G. Overall immunity. Br Dent J 2014; 216: 3.

DOI: $10.1038 / s j . b d j .2013 .1238$ 